\title{
Impact of partial nephrectomy on kidney function in patients with renal cell carcinoma
}

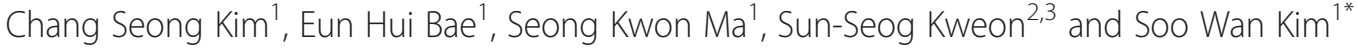

\begin{abstract}
Background: This study aimed to compare the changes in kidney function and the association of tumor size and renal outcomes between patients with renal cell carcinoma (RCC) who underwent radical nephrectomy (RN) and those who underwent partial nephrectomy (PN).

Methods: A retrospective cohort study was conducted for 557 patients with an RCC of $\leq 7 \mathrm{~cm}$ in diameter and normal contralateral kidney function who underwent PN or RN. PN was performed for 218 (39\%) patients. Renal outcomes included the incidence of acute kidney injury (AKI), new-onset chronic kidney disease (CKD), and a $\geq 25 \%$ decline in eGFR 1 year after surgery.

Results: Serial changes in eGFR were compared during the 3 years of follow-up. Postoperative eGFR was significantly lower in patients undergoing RN than in those undergoing PN. The incidence of AKI and new-onset CKD was significantly higher in patients after RN $(70.1 \%$ vs. $24.3 \%$, respectively; $P<0.001)$ than after PN $(55.7 \%$ vs. $6.2 \%$, respectively; $P<0.001$ ). According to the multivariable logistic regression analysis, $\mathrm{RN}$ was an independent risk factor for a $\geq 25 \%$ decline in kidney function after 1 year regardless of the tumor size, even after adjusting for various covariates.

Conclusions: Compared to PN, RN for even a moderate sized RCC leads to an increased incidence of AKI and new-onset CKD, and is a significant risk factor for kidney function decline. Therefore, PN should be considered as the choice of surgical treatment for RCCs that are $\leq 7 \mathrm{~cm}$ in diameter in order to preserve renal function postoperatively.
\end{abstract}

Keywords: Kidney function, Nephrectomy, Renal cell carcinoma

\section{Background}

Kidney cancer is the 13th most common malignancy worldwide and ranks 3rd among the leading causes of genitourinary cancers in Korea [1]. Renal cell carcinoma (RCC) accounts for approximately $90 \%$ of all renal malignancies. Although the incidence of RCC is declining in some European countries in recent years, a worldwide increase in RCC has been observed during the last decade [2].

Recently, the development and widespread use of imaging technologies have led to a decrease in the size and stage migration of newly detected renal cortical tumors. In the last two decades, increased detection of small renal masses has led to a greater utilization of partial nephrectomy (PN). In patients with small renal cortical tumors,

\footnotetext{
* Correspondence: skimw@chonnam.ac.kr

'Department of Internal Medicine, Chonnam National University Medical

School, 42 Jebongro, Gwangju 501-757, Korea

Full list of author information is available at the end of the article
}

radical nephrectomy $(\mathrm{RN})$ is a significantly independent risk factor for the development of chronic kidney disease (CKD) than PN [3,4]. Preserving the renal parenchyma by $\mathrm{PN}$ should be considered in most patients with small renal tumors because the decreased kidney function following $\mathrm{RN}$ might increase the risk for cardiovascular events and overall mortality in the long-term [5-7]. Although it has been shown that the development of CKD or decreased kidney function is higher in patients with RCC after RN than PN $[8,9]$, the renal outcomes between $\mathrm{RN}$ and $\mathrm{PN}$ are not well-understood in these patients. In addition, researchers of a recent study demonstrated that the incidence of CKD increased as the renal cortical tumor size decreased following $\mathrm{RN}$ [10]. However, data on the changes of kidney function after RN or PN in patients with renal tumors $>4 \mathrm{~cm}$ are currently limited [11,12].

We hypothesized that RN influences the risk for deleterious renal outcomes for acute or chronic state patients 
with small and moderate sized RCCs. The aim of this study was to compare the changes in kidney function and various renal outcomes as well as the association of tumor size and renal outcomes between patients with RCC undergoing RN and those undergoing PN. We hope that the findings of this study will help enhance surgical treatment and improve clinical outcomes for patients with RCC.

\section{Methods}

\section{Study design and patient population}

The electronic medical records were reviewed for all adult patients undergoing RN or PN for kidney cancer between December 2003 and December 2012 at the Chonnam National University Hospital. Among the 916 patients identified, we excluded patients with bilateral tumors and benign renal masses $(n=263)$, end-stage renal disease (patients with a history of hemodialysis, peritoneal dialysis, or kidney transplantation; $\mathrm{n}=12$ ), an estimated glomerular filtration rate (eGFR) $<15 \mathrm{~mL} / \mathrm{min} / 1.73 \mathrm{~m}^{2}$ $(\mathrm{n}=1)$, a RCC $>7 \mathrm{~cm}$ in diameter $(\mathrm{n}=82)$, and those who had a nephrectomy for metastatic RCC $(n=1)$. A total of 557 patients were included in the final analysis. RN was conducted in patients with a tumor involving a more central position of the kidney, suspected lymph node involvement, and multiple tumors in a single kidney. Patients with a tumor of $<7 \mathrm{~cm}$ in size underwent a PN when it was technically feasible. Otherwise, the surgical modality was chosen at the discretion of the surgeon. Cases of death were ascertained by data linkage of the national death certificate database of Statistics Korea and the regional cancer registries. The waiver of informed patient consent and approval of the study protocol were obtained by the Institutional Review Board of Chonnam National University Hospital in 2014. This study was conducted according to the principles of the Declaration of Helsinki.

\section{Data collection and definition}

Laboratory data regarding the levels of serum creatinine (SCr), hemoglobin, and urine protein were obtained from the medical records and reviewed by a trained study coordinator. SCr levels were measured at 6 time points (i.e., preoperatively, at 7 days, during discharge, and 3 months, 1 year, and 3 years after nephrectomy).

Tumor stage was reassessed according to the American Joint Committee on Cancer and the International Union for Cancer Control tumor-node-metastasis classification [13]. The Fuhrman grading system was used to measure nuclear grades [14]. To identify the impact of the type of surgery on renal outcomes according to the tumor size, we divided the patients into the following 2 groups: (1) tumor size $\leq 4 \mathrm{~cm}$ and (2) $4 \mathrm{~cm}<$ tumor size $\leq 7 \mathrm{~cm}$.

Acute kidney injury (AKI) was defined according to the Kidney Disease Improving Global Outcomes clinical practice guidelines. According to these guidelines, AKI is present when an abrupt reduction in kidney function results in an absolute increase in the SCr level by $\geq 0.3 \mathrm{mg} / \mathrm{dL}$ within 48 hours, a known or presumed $\geq 1.5$-fold increase in the baseline SCr level within the prior 7 days, or a reduction in urine output $(<0.5 \mathrm{~mL} / \mathrm{kg} / \mathrm{h})$ for 6 hours [15]. We did not consider the urine output criteria because retrospectively collected data can be inaccurate in this regard. AKI was further classified into the following 3 stages according to the severity of kidney injury: AKI stage 1 , increase in the $\mathrm{SCr}$ level by $\geq 0.3 \mathrm{mg} / \mathrm{dL}$ or $1.5-1.9$ times baseline; AKI stage 2, increase in the SCr level by 2.0-2.9 times baseline; and AKI stage 3, increase in the $\mathrm{SCr}$ level by $\geq 4.0 \mathrm{mg} / \mathrm{dL}$ or $\geq 3.0$ times baseline or initiation of renal replacement therapy. The patients who met the AKI criteria were further classified into the transient AKI (normalization of $\mathrm{SCr}$ level at discharge; $\mathrm{SCr}$ level $\leq 1.3 \mathrm{mg} / \mathrm{dL}$ ) and the persistent AKI (sustained elevation of SCr level at discharge; $\mathrm{SCr}$ level $>1.3 \mathrm{mg} / \mathrm{dL}$ ) groups.

New-onset CKD was defined as a decrease in the eGFR to $<60 \mathrm{~mL} / \mathrm{min} / 1.73 \mathrm{~m}^{2} 3$ months after nephrectomy in patients with a preoperative eGFR $>60 \mathrm{~mL} / \mathrm{min} /$ $1.73 \mathrm{~m}^{2}$.

\section{Assessment of renal function}

$\mathrm{SCr}$ levels were analyzed by the Jaffe method, which was calibrated by isotope dilution mass spectrometry. The eGFR (units $=\mathrm{mL} / \mathrm{min} / 1.73 \mathrm{~m}^{2}$ ) was calculated using the Chronic Kidney Disease Epidemiology Collaboration equation as follows: $141 \times$ minimum (creatinine $/ \mathrm{K}, 1)^{\alpha} \times$ maximum (creatinine $/ \mathrm{K}, 1)^{-1.209} \times 0.993^{\text {age }} \times 1.018$ (if female) $\times 1.159$ (if black), where $\mathrm{k}$ is 0.7 for women and 0.9 for men, and $\alpha$ is -0.329 for women and -0.411 for men [16].

\section{Statistical analysis}

Continuous variables were presented as mean \pm standard deviation and categorical variables were expressed as the number and percentage of patients. Comparative analysis was performed using Student's $t$-test for continuous variables and Pearson chi-square test for categorical variables. An analysis of covariance and multiple logistic regressions adjusted to age, sex, and proteinuria were performed to evaluate the changes in eGFR and renal outcomes (including AKI, new-onset CKD, and a $\geq 25 \%$ decline in eGFR after 1 year) between $\mathrm{RN}$ and PN at various time points. We performed a two-way analysis of variance (ANOVA) with repeated measures to compare the mean changes of eGFR over time between RN and $\mathrm{PN}$ according to tumor size. Within-group comparisons for eGFR at 7 days, 3 months, and 3 years were performed using a general linear model-ANOVA followed by a Bonferroni's correction applied to the post-hoc analysis 
for multiple comparisons using a pared $t$-test; a $P$ value of 0.017 was considered statistically significant. Multivariable logistic regression analyses were performed to identify the independent predictors of adverse renal outcomes according to tumor size after nephrectomy. Age, sex, blood pressure (systolic and diastolic), body mass index, history of smoking, hypertension, and diabetes mellitus, urine protein levels, type of surgical procedure, and the pathologic stage were all included in the multivariable logistic regression analysis. All statistical tests were 2 -tailed and $P<0.05$ was considered significant. The analyses were performed using the Statistical Package for Social Sciences software, version 17.0 (SPSS, Chicago, Illinois, USA).

\section{Results}

\section{Patient characteristics}

A total of 557 patients were included in the retrospective analysis. The mean age of the patients was 60.7 years, $393(70.6 \%)$ patients were male, and the mean baseline eGFR was $81.5 \pm 16.7 \mathrm{~mL} / \mathrm{min} / 1.73 \mathrm{~m}^{2}$. RN and PN were performed in 339 (61\%) and 218 (39\%) patients, respectively. The clinical characteristics of the patients with RCC are listed in Table 1 according to the type of surgery. Compared to patients undergoing $\mathrm{RN}$, those undergoing PN were more likely to have lower systolic and diastolic blood pressures $(130 \pm 14 \mathrm{mmHg}$ and $82 \pm$ $10 \mathrm{mmHg}$ vs. $133 \pm 14 \mathrm{mmHg}$ and $84 \pm 10 \mathrm{mmHg}$, respectively) and higher baseline eGFR $(83.9 \pm 15.1 \mathrm{~mL} /$ $\min / 1.73 \mathrm{~m}^{2}$ vs. $80.1 \pm 17.6 \mathrm{~mL} / \mathrm{min} / 1.73 \mathrm{~m}^{2}$, respectively). However, there were no differences between the RN and PN groups for age, sex, body mass index, hemoglobin levels, degree of urine protein, and a history of hypertension, diabetes, coronary artery disease, cerebral vascular disease, and smoking. Apart from the tumor size and pathologic stage, there were no significant differences in pathological characteristics (including tumor location, histological subtypes, and Fuhrman grade) between the RN and PN groups (Table 2). Open surgery was performed more frequently in the PN group compared to the RN group ( $22.9 \%$ vs. $13.6 \%$, respectively; $P=0.004)$. The overall recurrence rate was greater in the RN group than in the PN group $(11.2 \%$ vs. $3.2 \%$, respectively; $P=0.001)$. However, there was no difference in recurrence rate at the ipsilateral or contralateral kidney between the RN and PN groups (4.1\% vs. $1.8 \%$, respectively; $P=0.150$ ).

\section{Changes of renal function after PN or RN}

Serial changes in the mean eGFR from before surgery to the time points following surgery (i.e., 7 days, at discharge,

Table 1 Baseline clinical characteristics

\begin{tabular}{|c|c|c|c|c|}
\hline & All patients $(n=557)$ & RN ( $n=339)$ & PN $(n=218)$ & $P$ value \\
\hline Age (years) & $60.7 \pm 12.3$ & $61.0 \pm 12.8$ & $60.3 \pm 11.4$ & 0.495 \\
\hline Male (\%) & $393(70.6)$ & $234(69.0)$ & $159(72.9)$ & 0.323 \\
\hline Systolic blood pressure (mmHg) & $132 \pm 14$ & $133 \pm 14$ & $130 \pm 14$ & 0.027 \\
\hline Diastolic blood pressure $(\mathrm{mmHg})$ & $83 \pm 10$ & $84 \pm 10$ & $82 \pm 10$ & 0.015 \\
\hline Body mass index $\left(\mathrm{kg} / \mathrm{m}^{2}\right)$ & $24.4 \pm 3.1$ & $24.4 \pm 3.1$ & $24.3 \pm 3.0$ & 0.748 \\
\hline Diabetes (\%) & 89 (15.9) & $55(16.1)$ & $34(15.7)$ & 0.885 \\
\hline Hypertension (\%) & $220(39.4)$ & $139(40.8)$ & $81(37.3)$ & 0.418 \\
\hline Coronary artery disease (\%) & $25(4.5)$ & $13(3.8)$ & $12(5.5)$ & 0.339 \\
\hline Cerebral vascular disease (\%) & $15(2.7)$ & $7(2.1)$ & $8(3.7)$ & 0.247 \\
\hline History of Smoking (\%) & & & & 0.061 \\
\hline Never smoked & $342(61.4)$ & $203(59.9)$ & $139(63.8)$ & 0.359 \\
\hline Ex-smoker & $104(18.7)$ & $58(17.1)$ & $46(21.1)$ & 0.238 \\
\hline Current smoker & $111(19.9)$ & $78(23.0)$ & $33(15.1)$ & 0.023 \\
\hline Hemoglobin (mg/dL) & $13.9 \pm 1.7$ & $13.8 \pm 1.7$ & $14.1 \pm 1.5$ & 0.097 \\
\hline Urine protein (grade) ${ }^{a}$ & & & & 0.124 \\
\hline 0 & $482(86.7)$ & $286(84.6)$ & $196(89.9)$ & 0.073 \\
\hline $1-2$ & $51(9.2)$ & $32(9.5)$ & $19(8.8)$ & 0.764 \\
\hline $3-4$ & $23(4.2)$ & $20(5.9)$ & $3(1.4)$ & 0.008 \\
\hline Baseline creatinine $(\mathrm{mg} / \mathrm{dL})$ & $0.95 \pm 0.23$ & $0.97 \pm 0.25$ & $0.93 \pm 0.18$ & 0.021 \\
\hline Baseline eGFR ${ }^{b}$ & $81.5 \pm 16.7$ & $80.1 \pm 17.6$ & $83.9 \pm 15.1$ & 0.007 \\
\hline
\end{tabular}

${ }^{\mathrm{a}}$ Dip-stick test.

beGFR (mL/min/1.73 $\mathrm{m}^{2}$ ) calculated using the Chronic Kidney Disease-Epidemiology Collaboration equation. Abbreviations: eGFR estimated glomerular filtration rate, RN radical nephrectomy, PN partial nephrectomy. 
Table 2 Baseline pathological characteristics

\begin{tabular}{|c|c|c|c|c|}
\hline & All patients $(n=557)$ & RN (n= 339) & $\mathrm{PN}(n=218)$ & $P$ value \\
\hline Surgical approach (\%) & & & & 0.004 \\
\hline Open & $96(17.2)$ & 46 (13.6) & $50(22.9)$ & \\
\hline Laparoscopic & $461(82.8)$ & $293(86.4)$ & $168(77.1)$ & \\
\hline Tumor location (\%) & & & & 0.925 \\
\hline Right & $285(51.2)$ & $174(51.3)$ & $111(50.9)$ & \\
\hline Left & $272(48.8)$ & $165(48.7)$ & $107(49.1)$ & \\
\hline Tumor size $(\mathrm{cm})$ & $3.4 \pm 1.5$ & $4.1 \pm 1.4$ & $2.4 \pm 1.0$ & $<0.001$ \\
\hline$\leq 4$, No $(\%)$ & $370(66.4)$ & $167(49.3)$ & $203(93.1)$ & $<0.001$ \\
\hline $4<$ size $\leq 7$, No $(\%)$ & 187 (33.6) & $172(50.7)$ & $15(6.9)$ & $<0.001$ \\
\hline Histology (\%) & & & & 0.077 \\
\hline Clear cell & $439(79.0)$ & $270(79.9)$ & $167(77.5)$ & \\
\hline Papillary & $47(8.5)$ & $20(5.9)$ & $27(12.4)$ & \\
\hline Chromophobe & $43(7.7)$ & $29(8.6)$ & $14(6.5)$ & \\
\hline Other & $27(4.9)$ & $19(5.6)$ & $8(3.7)$ & \\
\hline Fuhrman grade (\%) & & & & 0.721 \\
\hline 1 & $68(12.2)$ & $38(11.2)$ & $30(13.8)$ & \\
\hline 2 & $358(64.3)$ & $218(64.3)$ & $140(64.2)$ & \\
\hline 3 & $109(19.6)$ & $67(19.8)$ & $42(19.3)$ & \\
\hline 4 & $12(2.2)$ & $9(2.7)$ & $3(1.4)$ & \\
\hline Pathologic stage $(\%)^{a}$ & & & & 0.005 \\
\hline । & $546(98.0)$ & $328(96.8)$ & $218(100)$ & \\
\hline III & $11(2.0)$ & $11(3.2)$ & & \\
\hline Nephrectomy size (cm) & $9.2 \pm 4.7$ & $12.5 \pm 2.2$ & $3.9 \pm 1.5$ & $<0.001$ \\
\hline
\end{tabular}

3 months, 1 year, and 3 years) according to the type of surgery (i.e., PN and RN) and tumor size $(\leq 4 \mathrm{~cm}$ and $4 \mathrm{~cm}<$ tumor size $\leq 7 \mathrm{~cm}$ ) are shown in Figure 1. The eGFR was significantly lower in patients undergoing $\mathrm{RN}$ than in those undergoing PN 3 years after surgery, even after adjusting for age and sex $(P<0.05)$, as determined using two-way ANOVA with repeated measure analysis. The RN and PN groups, categorized according to tumor size, also showed similar changes in eGFR after surgery, even though the baseline eGFR was not different between the 2 groups. The mean eGFR decreased from $80.1 \mathrm{~mL} / \mathrm{min} /$ $1.73 \mathrm{~m}^{2}$ before surgery to $56.2 \mathrm{~mL} / \mathrm{min} / 1.73 \mathrm{~m}^{2}$ at 3 months $(P<0.001)$ and then increased to $59.0 \mathrm{~mL} / \mathrm{min} /$ $1.73 \mathrm{~m}^{2} 3$ years after RN $(P=0.001)$. However, there were no significant changes in eGFR over time (i.e., from surgery to follow-up period) in patients with $\mathrm{PN}$.

\section{Renal outcomes after PN or RN}

As shown in Table 3, the incidence of AKI in patients undergoing RN was significantly higher than patients undergoing PN (70.1\% vs. $24.3 \%$, respectively; $P<0.001)$. Furthermore, the incidence of transient and persistent
AKI was significantly higher in patients undergoing RN than PN. In addition, compared to the PN group, the RN group had significantly higher prevalence of newonset CKD 3 months after the operation (55.7\% vs. $6.2 \%$, respectively; $P<0.001$ ) and a $\geq 25 \%$ decline in the eGFR after 1 year $(65.4 \%$ vs. $8.1 \%$, respectively; $P<0.001)$, even after adjusting for age, sex, and proteinuria. All-cause mortality was significantly higher in patients undergoing $\mathrm{RN}$ than in those undergoing $\mathrm{PN}(10.0 \%$ vs. $3.7 \%$; $P=0.006)$. Among these patients, there was 1 case of death in a patient undergoing $\mathrm{RN}$, who died due to endstage renal disease; no cases of deaths were observed in the PN group.

We identified independent risk factors for the adverse renal outcomes that were categorized according to the tumor size after nephrectomy by using multivariable logistic regression analysis (Table 4). Among the risk contributors in the total cohort (tumor size $\leq 7 \mathrm{~cm}$ ), RN was found to be the most important factor for the incidence of AKI, new-onset CKD, and a $\geq 25 \%$ decline in eGFR after 1 year. Furthermore, compared to patients undergoing $\mathrm{PN}$, those undergoing $\mathrm{RN}$ for tumors $\leq 4 \mathrm{~cm}$ and 


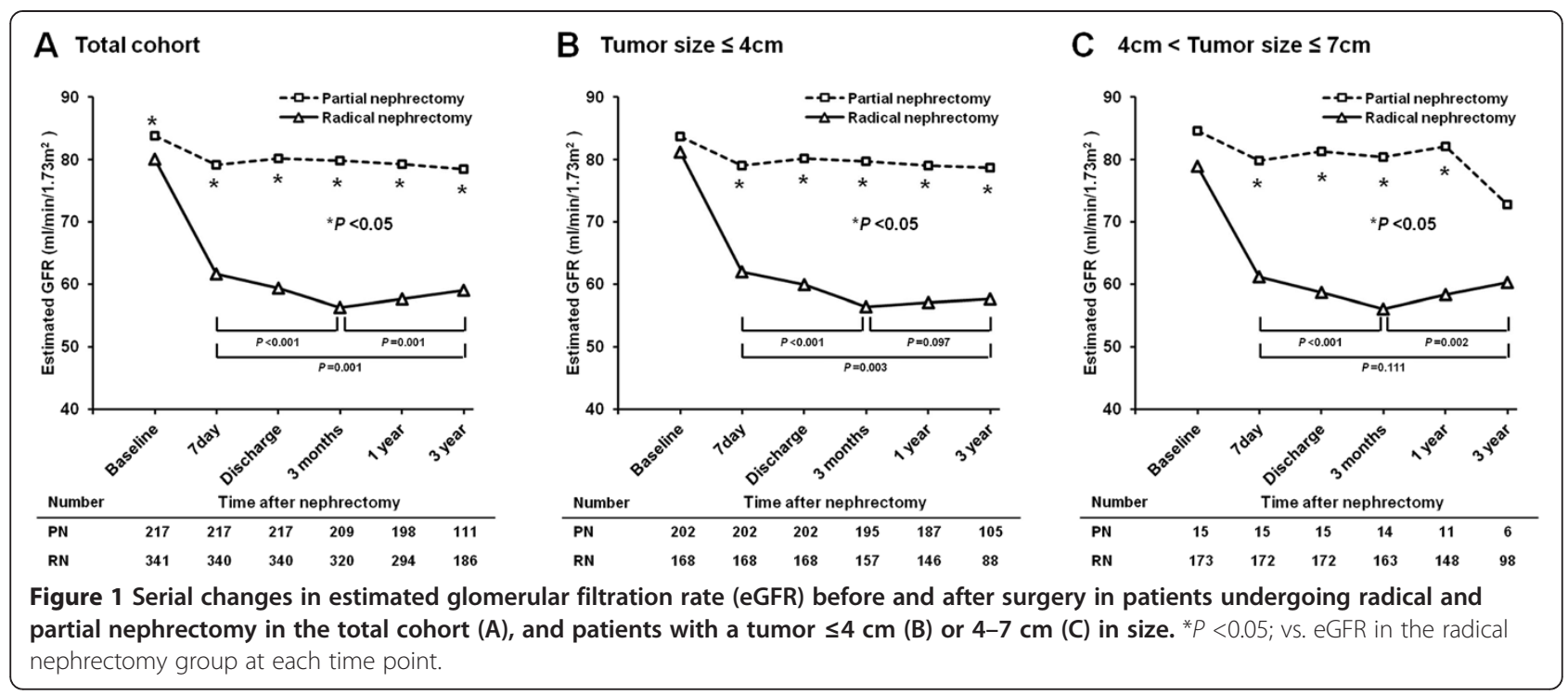

4-7 $\mathrm{cm}$ in size also had a higher risk of a $\geq 25 \%$ decline in eGFR after 1 year after multiple adjustments (odds ratio $[\mathrm{OR}]=28.3,95 \%$ confidence interval $[\mathrm{CI}]=14.3$ 56.0, $P<0.001 ; \mathrm{OR}=12.6 ; 95 \% \mathrm{CI}=1.45-108.9, P=$ 0.022 , respectively).

\section{Discussion}

In this study, we determined that the postoperative eGFR was significantly lower in patients undergoing RN than those undergoing PN during the 3 years follow-up period. Patients undergoing RN also had a higher risk of various adverse renal outcomes (i.e., AKI, new-onset CKD, and $\geq 25 \%$ decline in eGFR after 1 year) compared to those undergoing PN. Furthermore, $\mathrm{RN}$ increased the risk for deleterious renal outcomes for patients with small (tumor size $\leq 4 \mathrm{~cm}$ ) and moderately $(4 \mathrm{~cm}<$ tumor size $\leq 7 \mathrm{~cm}$ ) sized RCCs. Therefore, our hypothesis that $\mathrm{RN}$ increases the risk for deleterious renal outcomes for acute or chronic state patients with small and moderately sized RCCs is supported by the findings of the present study.

RN is now recognized as an independent risk factor for the development of CKD when used as a treatment for small renal tumors $[8,10]$. Nevertheless, $\mathrm{RN}$ remained the most common treatment for newly detected small renal tumors over the last decade. A recent meta-analysis showed that PN confers a survival advantage and a lower risk of severe CKD (eGFR $<60 \mathrm{~mL} / \mathrm{min} / 1.73 \mathrm{~m}^{2}$ ) after operation for localized renal tumors [17]. Although RN accounts for up to $60 \%$ of all nephrectomies in our cohort, we also found that the incidence of new-onset CKD was higher in patients undergoing $\mathrm{RN}$ than those who were undergoing $\mathrm{PN}$ (55.7\% vs. 6.2\%, respectively). However, most studies have investigated the development of CKD at irregular time points after nephrectomy, and there are limited data regarding AKI or kidney function decline after

Table 3 Renal outcomes after radical and partial nephrectomy adjusted for age, sex, and proteinuria

\begin{tabular}{|c|c|c|c|c|}
\hline & All patients $(n=557)$ & $\mathrm{RN}(\mathrm{n}=339)$ & PN $(n=218)$ & $P$ value $^{\mathrm{a}}$ \\
\hline$\overline{A K I}(\%)^{b}$ & $290(52.2)$ & $237(70.1)$ & $53(24.3)$ & $<0.001$ \\
\hline Stage 1 & $265(47.7)$ & $217(91.6)$ & $48(90.1)$ & $<0.001$ \\
\hline Stage 2 & $19(3.4)$ & $16(6.7)$ & $3(5.6)$ & 0.033 \\
\hline Stage 3 & $6(1.1)$ & $4(1.7)$ & $2(3.8)$ & 1.000 \\
\hline Transient AKI (\%) & $173(31.1)$ & $124(36.7)$ & $49(22.5)$ & $<0.001$ \\
\hline Persistent AKI (\%) & $117(21.0)$ & $113(33.4)$ & $4(1.8)$ & $<0.001$ \\
\hline New-onset CKD $(\%)^{c}$ & $190(36.0)$ & $177(55.7)$ & $13(6.2)$ & $<0.001$ \\
\hline$\geq 25 \%$ decline in eGFR 1 year after surgery (\%) ${ }^{d}$ & $207(42.2)$ & $191(65.4)$ & $16(8.1)$ & $<0.001$ \\
\hline All-cause mortality & $42(7.5)$ & $34(10.0)$ & $8(3.7)$ & 0.006 \\
\hline
\end{tabular}

${ }^{\mathrm{a} P}$ value by age, sex and proteinruia-adjusted logistic regression.

${ }^{b}$ Defined by Kidney Disease: Improving Global Outcomes guideline.

${ }^{c}$ eGFR $<60 \mathrm{~mL} / \mathrm{min} / 1.73 \mathrm{~m}^{2}$ after 3 months postoperatively, calculated using the Chronic Kidney Disease-Epidemiology Collaboration equation.

deGFR $\left(\mathrm{mL} / \mathrm{min} / 1.73 \mathrm{~m}^{2}\right)$, calculated using the Chronic Kidney Disease-Epidemiology Collaboration equation.

Abbreviations: eGFR estimated glomerular filtration rate, AKI acute kidney injury, CKD chronic kidney disease, RN radical nephrectomy, PN partial nephrectomy. 
Table 4 Multivariable logistic regression analysis of renal outcomes categorized by tumor size after nephrectomy

\begin{tabular}{|c|c|c|c|c|c|c|}
\hline & \multicolumn{2}{|c|}{$\begin{array}{l}\text { Total cohort } \\
(n=557)\end{array}$} & \multicolumn{2}{|c|}{$\begin{array}{c}\text { Tumor size } \leq 4 \mathrm{~cm} \\
(\mathrm{n}=370)\end{array}$} & \multicolumn{2}{|c|}{$\begin{array}{c}4 \mathrm{~cm}<\text { tumor size } \leq 7 \mathrm{~cm} \\
(\mathrm{n}=187)\end{array}$} \\
\hline & OR (Cl 95\%) & $P$ value & OR (Cl 95\%) & $P$ value & OR (Cl 95\%) & $P$ value \\
\hline \multicolumn{7}{|l|}{ AKI } \\
\hline Age & $0.99(0.97-1.00)$ & 0.149 & $0.99(0.97-1.01)$ & 0.398 & $0.98(0.96-1.01)$ & 0.210 \\
\hline Male & $3.15(1.92-5.17)$ & $<0.001$ & $3.58(1.86-6.91)$ & $<0.001$ & $2.24(1.13-5.26)$ & 0.023 \\
\hline BMI & $1.11(1.04-1.19)$ & 0.002 & $1.09(1.00-1.19)$ & 0.054 & $1.14(1.02-1.27)$ & 0.019 \\
\hline Smoking & $1.01(0.64-1.59)$ & 0.976 & $0.80(0.45-1.40)$ & 0.429 & $1.56(0.69-3.50)$ & 0.283 \\
\hline Hypertension & $1.39(0.89-2.18)$ & 0.144 & $1.38(0.78-2.45)$ & 0.275 & $1.43(0.69-2.97)$ & 0.338 \\
\hline Diabetes & $0.68(0.38-1.21)$ & 0.188 & $0.56(0.27-1.17)$ & 0.122 & $0.98(0.36-2.70)$ & 0.967 \\
\hline Proteinuria & $1.00(0.54-1.85)$ & 0.994 & $1.08(0.49-0.34)$ & 0.859 & $0.87(0.31-2.48)$ & 0.796 \\
\hline Open surgery & $1.06(0.63-1.79)$ & 0.829 & $1.04(0.54-2.01)$ & 0.901 & $1.15(0.46-2.85)$ & 0.770 \\
\hline Stage III & $0.69(0.18-2.58)$ & 0.576 & $0.43(0.02-8.43)$ & 0.575 & $0.93(0.19-4.67)$ & 0.931 \\
\hline Partial nephrectomy & 1 [Reference] & & 1 [Reference] & & 1 [Reference] & \\
\hline Radical nephrectomy & $9.57(6.20-14.8)$ & $<0.001$ & $12.8(7.09-20.7)$ & $<0.001$ & $5.49(1.52-19.9)$ & 0.009 \\
\hline \multicolumn{7}{|l|}{ New-onset CKD } \\
\hline Age & 1.06 (1.04-1.08) & $<0.001$ & $1.06(1.03-1.09)$ & $<0.001$ & $1.06(1.03-1.10)$ & $<0.001$ \\
\hline Male & $1.04(0.60-1.78)$ & 0.898 & $0.99(0.46-2.13)$ & 0.988 & $1.01(0.45-2.24)$ & 0.988 \\
\hline BMI & $1.00(0.92-1.07)$ & 0.884 & $0.99(0.89-1.10)$ & 0.879 & $0.97(0.87-1.08)$ & 0.580 \\
\hline Smoking & $1.49(-0.89-2.51)$ & 0.131 & $1.62(0.80-3.25)$ & 0.178 & $1.60(0.70-3.67)$ & 0.266 \\
\hline Hypertension & $0.87(0.54-1.41)$ & 0.564 & $0.98(0.50-1.90)$ & 0.943 & $0.70(0.33-1.47)$ & 0.345 \\
\hline Diabetes & $1.52(0.81-2.84)$ & 0.190 & $0.97(0.42-2.23)$ & 0.940 & $3.38(1.13-10.1)$ & 0.030 \\
\hline Proteinuria & $0.93(0.48-1.78)$ & 0.815 & $1.08(0.46-2.52)$ & 0.859 & $0.81(0.26-2.54)$ & 0.722 \\
\hline Open surgery & $0.95(0.49-1.83)$ & 0.874 & $1.31(0.54-3.18)$ & 0.555 & $0.57(0.21-1.54)$ & 0.266 \\
\hline Stage III & $0.44(0.11-1.84)$ & 0.262 & $1.36(0.08-24.1)$ & 0.836 & $0.27(0.05-1.48)$ & 0.131 \\
\hline Partial nephrectomy & 1 [Reference] & & 1 [Reference] & & 1 [Reference] & \\
\hline Radical nephrectomy & 23.7(11.7-41.0) & $<0.001$ & $24.9(11.7-49.7)$ & $<0.001$ & $7.03(1.18-31.3)$ & 0.031 \\
\hline \multicolumn{7}{|c|}{$\geq 25 \%$ decline in eGFR 1 year after surgery } \\
\hline Age & $1.01(0.99-1.03)$ & 0.309 & $1.01(0.99-1.04)$ & 0.371 & $1.01(0.98-1.04)$ & 0.655 \\
\hline Male & $1.58(0.91-2.74)$ & 0.104 & $1.99(0.92-4.29)$ & 0.081 & $1.03(0.45-2.38)$ & 0.944 \\
\hline BMI & $1.05(0.97-1.13)$ & 0.220 & $1.02(0.92-1.13)$ & 0.712 & $1.06(0.94-1.19)$ & 0.362 \\
\hline Smoking & $1.10(0.65-1.83)$ & 0.731 & $0.77(0.38-1.55)$ & 0.469 & $1.85(0.89-4.33)$ & 0.158 \\
\hline Hypertension & $0.85(0.51-1.41)$ & 0.527 & $0.68(0.35-1.36)$ & 0.277 & $1.07(0.48-2.40)$ & 0.868 \\
\hline Diabetes & $1.57(0.81-3.03)$ & 0.178 & $1.64(0.69-3.86)$ & 0.261 & $1.50(0.50-4.49)$ & 0.472 \\
\hline Proteinuria & $0.99(0.50-1.96)$ & 0.971 & $1.24(0.50-3.07)$ & 0.638 & $0.95(0.31-2.95)$ & 0.930 \\
\hline Open surgery & $0.57(0.29-1.12)$ & 0.102 & $1.12(0.46-2.74)$ & 0.805 & $0.24(0.08-0.73)$ & 0.011 \\
\hline Stage III & $0.77(0.16-3.71)$ & 0.742 & $0.55(0.03-10.5)$ & 0.690 & $0.69(0.09-5.10)$ & 0.712 \\
\hline Partial nephrectomy & 1 [Reference] & & 1 [Reference] & & 1 [Reference] & \\
\hline Radical nephrectomy & $22.7(12.7-40.7)$ & $<0.001$ & $28.3(14.3-56.0)$ & $<0.001$ & $12.6(1.45-108.9)$ & 0.022 \\
\hline
\end{tabular}

Adjusted factors include age, sex, systolic blood pressure, diastolic blood pressure, body mass index, history of smoking, hypertension, and diabetes mellitus, urine protein level, type of surgical procedure, and pathologic stage.

Abbreviations: OR odds ratio, Cl confidential interval, AKI acute kidney injury, CKD chronic kidney disease, eGFR estimated glomerular filtration rate, BMI body mass index.

operation $[3-5,8,11,18]$. We showed that the incidence of AKI was higher in the RN group compared to the PN group. Interestingly, persistence AKI at discharge was high as $33.4 \%$ in patients after $\mathrm{RN}$, while it was as low as $1.8 \%$ in patients after PN. These findings are in accordance with another study, which conclude that postoperative AKI in patients with RCC is associated with new-onset CKD after RN [19]. Researchers of recent studies have showed that 
AKI increases the risk of CKD and end-stage renal disease [20-22]. Furthermore, patients who underwent RN had a higher risk of $\geq 25 \%$ decline in kidney function after 1 year than those who underwent PN. Consequently, RN might have influenced the postoperative acute and long-term kidney injury in patients with RCC. According to these changes, PN would be the preferred surgical treatment modality for treating RCC rather than RN because of the advantage of preserving renal function after the operation [23]. The cancer-specific survival for patients with small renal cortical tumors is $>90 \%$ across all histological subtypes and therefore, there is a need for long-term management of postoperative complication (i.e., decreased kidney function) [24].

Complete surgical excision by $\mathrm{PN}$ is recommended for patients with all clinical T1 kidney tumors (i.e., tumor size $<7 \mathrm{~cm}$ ) based on compelling data demonstrating that $\mathrm{RN}$ is associated with an increased risk of CKD $[25,26]$. Interestingly, it has been reported that as the tumor size decreased, the risk of new-onset CKD increased in patients undergoing RN for RCC [10]. However, only a few studies have been published regarding the link between large tumor sizes and decreased kidney function after RN or PN. In a few retrospective studies, $\mathrm{RN}$ was found to be associated with the development of CKD in patients treated for renal tumors of $4-7 \mathrm{~cm}$ in size [11,12,27]. In this regard, our findings are consistent with the idea that compared to $\mathrm{PN}, \mathrm{RN}$ is associated with AKI, kidney function decline, and new-onset CKD in patients with moderate sized renal tumors (i.e., $4 \mathrm{~cm} \leq$ tumor size $<7 \mathrm{~cm}$ ). If technically feasible, PN might enable a better preservation of postoperative kidney function and also prevent the development of AKI or CKD for patients with tumors that are up to $7 \mathrm{~cm}$ in size.

A lower eGFR before surgery would affect the postoperative kidney function. Although the preoperative eGFR was significantly lower in patients undergoing RN than in those undergoing PN in the total cohort, which might be due to the fact that $\mathrm{RN}$ was performed more frequently in patients with RCC $>4 \mathrm{~cm}$ in size, there was a correlation between increased tumor size and decreased preoperative eGFR [10]. However, there are no significant differences in preoperative eGFR between the patients in the RN and PN groups according to tumor size. Therefore, the effect of tumor size on preoperative eGFR would be attenuated when patients were categorized into the 2 groups by a tumor size $>4 \mathrm{~cm}$. Nevertheless, the RN group showed a greater decline in eGFR than the PN group during the 3-year postoperative follow-up period.

According to two retrospective studies, compensatory hypertrophy in the non-operated healthy kidney occurs between 7 days and 4 weeks after RN [10,28]. However, unlike previous reports, we showed that the non- operated healthy kidney experiences an adaptation in renal function 3 months after RN. Therefore, we should monitor renal function until at least 3 months after RN to prevent further renal injury. In addition, a higher resistive index on duplex ultrasonography, which was not performed in this study, may be helpful for predicting AKI and CKD progression after surgery [29].

The present study has several limitations. Firstly, our study was of retrospective nature and therefore, our findings may be affected by confounding factors or selection bias. Secondly, we could not evaluate the nonneoplastic kidney disease, which may have had an effect on kidney function decline in patients with RCC after nephrectomy. However, there were no differences in comorbidities (i.e., prevalence of hypertension and diabetes that could lead to parenchyma kidney diseases) between patients undergoing RN and PN in this study. Thirdly, long-term renal outcomes could not be fully evaluated despite checking the eGFR at various time points after the operations.

Despite these limitations, our study had some strengths. Firstly, we used the recently validated Chronic Kidney Disease Epidemiology Collaboration equation to calculate the eGFR, while most previous studies involved the Modification of Diet in Renal Disease equation that systematically underestimates GFR in individuals without known CKD [30]. Secondly, we evaluated various renal outcomes including AKI, CKD, and kidney function decline to determine the clinical impact of the surgical procedures. Finally, we collected data regarding the degree of proteinuria in our patients and included these in our analyses for adjustment, which may affect overall kidney function.

\section{Conclusions}

The risk for the incidence of AKI, new-onset CKD, and kidney function decline in patients undergoing $\mathrm{RN}$ was higher than that of patients undergoing PN even for moderately sized RCC tumors. Therefore, PN should be considered as the surgical treatment of choice for RCCs up to $7 \mathrm{~cm}$ in size, which will allow for the preservation of renal function postoperatively.

\section{Abbreviations}

RCC: Renal cell carcinoma; PN: Partial nephrectomy; RN: Radical nephrectomy; CKD: Chronic kidney disease; eGFR: Estimated glomerular filtration rate; SCr: Serum creatinine; AKI: Acute kidney injury; ANOVA: Analysis of variance.

\section{Competing interests}

The authors declare that they have no competing interests.

\section{Authors' contributions}

CSK carried out the research design, performed the statistical analysis and final preparation of the manuscript; EHB participated in the design of this study; SKM participated in its design and coordination and helped to draft the manuscript; SSK participated in death data acquisition; SWK contributed in the research design, results interpretation and final preparation of the manuscript. All authors read and approved the final manuscript. 


\section{Acknowledgements}

This study was supported by a grant (CRI13903-21) Chonnam National University Hospital Biomedical Research Institute.

\section{Author details}

${ }^{1}$ Department of Internal Medicine, Chonnam National University Medical School, 42 Jebongro, Gwangju 501-757, Korea. ${ }^{2}$ Department of Preventive Medicine, Chonnam National University Medical School, Gwangju, Korea. ${ }^{3}$ Jeonnam Regional Cancer Center, Chonnam National University Hwasun Hospital, Hwasun, Republic of Korea.

Received: 25 July 2014 Accepted: 10 November 2014

Published: 19 November 2014

\section{References}

1. Ferlay J, Shin HR, Bray F, Forman D, Mathers C, Parkin DM: Estimates of worldwide burden of cancer in 2008: GLOBOCAN 2008. Int J Cancer 2010, 127:2893-2917.

2. Ljungberg B, Campbell SC, Choi HY, Jacamin D, Lee JE, Weikert S, Kiemeney LA: The epidemiology of renal cell carcinoma. Eur Urol 2011, 60:615-621.

3. Huang WC, Levey AS, Serio AM, Snyder M, Vickers AJ, Raj GV, Scardino PT, Russo P: Chronic kidney disease after nephrectomy in patients with renal cortical tumours: a retrospective cohort study. Lancet Oncol 2006, 7:735-740.

4. Kim SH, Lee SE, Hong SK, Jeong CW, Park YH, Kim YJ, Kang SH, Hong SH, Choi WS, Byun SS: Incidence and risk factors of chronic kidney disease in korean patients with t1a renal cell carcinoma before and after radical or partial nephrectomy. Jpn J Clin Oncol 2013, 43:1243-1248.

5. Huang WC, Elkin EB, Levey AS, Jang TL, Russo P: Partial nephrectomy versus radical nephrectomy in patients with small renal tumors-is there a difference in mortality and cardiovascular outcomes? J Urol 2009, 181:55-61. discussion 61-52.

6. Thompson RH, Boorjian SA, Lohse CM, Leibovich BC, Kwon ED, Cheville JC, Blute ML: Radical nephrectomy for pT1a renal masses may be associated with decreased overall survival compared with partial nephrectomy. J Urol 2008, 179:468-471. discussion 472-463.

7. Becker F, Siemer S, Humke U, Hack M, Ziegler M, Stockle M: Elective nephron sparing surgery should become standard treatment for small unilateral renal cell carcinoma: Long-term survival data of 216 patients. Eur Urol 2006, 49:308-313.

8. Scosyrev E, Messing EM, Sylvester R, Campbell S, Van Poppel H: Renal function after nephron-sparing surgery versus radical nephrectomy: results from EORTC randomized trial 30904. Eur Urol 2014, 65:372-377.

9. Miyamoto K, Inoue S, Kajiwara M, Teishima J, Matsubara A: Comparison of renal function after partial nephrectomy and radical nephrectomy for renal cell carcinoma. Urol Int 2012, 89:227-232.

10. Jeon HG, Choo SH, Sung HH, Jeong BC, Seo SI, Jeon SS, Choi HY, Lee HM: Small tumour size is associated with new-onset chronic kidney disease after radical nephrectomy in patients with renal cell carcinoma. Eur J Cancer 2014, 50:64-69.

11. Roos FC, Brenner W, Thomas C, Jager W, Thuroff JW, Hampel C, Jones J: Functional analysis of elective nephron-sparing surgery vs radical nephrectomy for renal tumors larger than $4 \mathrm{~cm}$. Urology 2012, 79:607-613.

12. Thompson $\mathrm{RH}$, Siddiqui S, Lohse CM, Leibovich BC, Russo P, Blute ML: Partial versus radical nephrectomy for 4 to $7 \mathrm{~cm}$ renal cortical tumors. J Urol 2009, 182:2601-2606.

13. Edge SB, American Joint Committee on Cancer: AJCC Cancer Staging Manual. 7th edition. New York: Springer; 2010.

14. Fuhrman SA, Lasky LC, Limas C: Prognostic significance of morphologic parameters in renal cell carcinoma. Am J Surg Pathol 1982, 6:655-663.

15. Kellum JA, Lameire N: Diagnosis, evaluation, and management of acute kidney injury: a KDIGO summary (Part 1). Crit Care 2013, 17:204.

16. Levey AS, Stevens LA, Schmid CH, Zhang YL, Castro AF 3rd, Feldman HI, Kusek JW, Eggers P, Van Lente F, Greene T, Coresh J: A new equation to estimate glomerular filtration rate. Ann Intern Med 2009, 150:604-612.

17. Kim SP, Thompson RH, Boorjian SA, Weight CJ, Han LC, Murad MH, Shippee ND, Erwin PJ, Costello BA, Chow GK, Leibovich BC: Comparative effectiveness for survival and renal function of partial and radical nephrectomy for localized renal tumors: a systematic review and meta-analysis. J Urol 2012, 188:51-57.

18. Takagi T, Kondo T, lizuka J, Kobayashi H, Hashimoto Y, Nakazawa H, Ito F, Tanabe K: Postoperative renal function after partial nephrectomy for renal cell carcinoma in patients with pre-existing chronic kidney disease: a comparison with radical nephrectomy. Int J Urol 2011, 18:472-476.

19. Cho A, Lee JE, Kwon GY, Huh W, Lee HM, Kim YG, Kim DJ, Oh HY, Choi HY: Post-operative acute kidney injury in patients with renal cell carcinoma is a potent risk factor for new-onset chronic kidney disease after radical nephrectomy. Nephrol Dial Transplant 2011, 26:3496-3501.

20. Okusa MD, Chertow GM, Portilla D: The nexus of acute kidney injury, chronic kidney disease, and World Kidney Day 2009. Clin J Am Soc Nephrol 2009, 4:520-522.

21. Lo LJ, Go AS, Chertow GM, McCulloch CE, Fan D, Ordonez JD, Hsu CY: Dialysis-requiring acute renal failure increases the risk of progressive chronic kidney disease. Kidney Int 2009, 76:893-899.

22. Hsu CY: Linking the population epidemiology of acute renal failure, chronic kidney disease and end-stage renal disease. Curr Opin Nephrol Hypertens 2007, 16:221-226.

23. Pettus JA, Jang TL, Thompson RH, Yossepowitch O, Kagiwada M, Russo P: Effect of baseline glomerular filtration rate on survival in patients undergoing partial or radical nephrectomy for renal cortical tumors. Mayo Clin Proc 2008, 83:1101-1106.

24. Patard JJ, Shvarts O, Lam JS, Pantuck AJ, Kim HL, Ficarra V, Cindolo L, Han KR, De La Taille A, Tostain J, Artibani W, Abbou CC, Lobel B, Chopin DK, Figlin RA, Mulders PF, Belldegrun AS: Safety and efficacy of partial nephrectomy for all $\mathrm{T} 1$ tumors based on an international multicenter experience. J Urol 2004, 171:2181-2185. quiz 2435.

25. Campbell SC, Novick AC, Belldegrun A, Blute ML, Chow GK, Derweesh $\mathbb{H}_{\text {, }}$ Faraday MM, Kaouk JH, Leveillee RJ, Matin SF, Russo P, Uzzo RG, Practice Guidelines Committee of the American Urological Association: Guideline for management of the clinical T1 renal mass. J Urol 2009, 182:1271-1279.

26. Ljungberg B, Cowan NC, Hanbury DC, Hora M, Kuczyk MA, Merseburger AS, Patard JJ, Mulders PF, Sinescu IC: EAU guidelines on renal cell carcinoma: the 2010 update. Eur Urol 2010, 58:398-406.

27. Dash A, Vickers AJ, Schachter LR, Bach AM, Snyder ME, Russo P: Comparison of outcomes in elective partial vs radical nephrectomy for clear cell renal cell carcinoma of 4-7 cm. BJU Int 2006, 97:939-945.

28. Tanaka N, Fujimoto K, Tani M, Yoshii M, Yoshida K, Hirao Y, Ozono S: Prediction of postoperative renal function by preoperative serum creatinine level and three-dimensional diagnostic image reconstruction in patients with renal cell carcinoma. Urology 2004, 64:904-908.

29. Kim ES, Kim HJ, Kim YJ, Lee SM, Lee HJ, Cho DS, Son YK, Kim SE, Kim KH, An WS: Resistive index as a predictor of acute kidney injury caused by an angiotensin converting enzyme inhibitor or angiotensin II receptor blocker in chronic kidney disease patients. Kidney Res Clin Pract 2013, 32:158-163.

30. Stevens LA, Schmid CH, Greene T, Zhang YL, Beck GJ, Froissart M, Hamm LL, Lewis JB, Mauer M, Navis GJ, Steffes MW, Eggers PW, Coresh J, Levey AS: Comparative performance of the CKD epidemiology collaboration (CKD-EPI) and the modification of diet in renal disease (MDRD) study equations for estimating GFR levels above $60 \mathrm{~mL} / \mathrm{min} / 1.73 \mathrm{~m} 2$. Am J Kidney Dis 2010, 56:486-495.

doi:10.1186/1471-2369-15-181

Cite this article as: Kim et al.: Impact of partial nephrectomy on kidney function in patients with renal cell carcinoma. BMC Nephrology 2014 15:181

\section{Submit your next manuscript to BioMed Central and take full advantage of:}

- Convenient online submission

- Thorough peer review

- No space constraints or color figure charges

- Immediate publication on acceptance

- Inclusion in PubMed, CAS, Scopus and Google Scholar

- Research which is freely available for redistribution 